\title{
A LEI DO ESTÁGIO E SUA APLICABILIDADE: UMA ANÁLISE BASEADA NOS ESTAGIÁRIOS DO CURSO DE DIREITO DA FURG
}

Caroline Soares Gonçalves*

Eder Dion de Paula Costa ${ }^{* *}$

\begin{abstract}
RESUMO
Este artigo tem como principal objetivo analisar a aplicação da lei do estágio e a contribuição para a regulação dos estágios vivenciados pelos discentes do Curso de Direito da Universidade Federal de Rio Grande - Furg. Trata-se de uma pesquisa desenvolvida para avaliar qualitativamente a realização dos estágios. No que tange aos aspectos estruturais, ainda na parte introdutória, são feitas considerações a respeito do contexto global e o perfil do estagiário de Direito com base no estímulo ao desenvolvimento de novas competências. Como foco da avaliação do cumprimento da lei do estágio e satisfação dos estagiários, o trabalho faz uma crítica à falta de fiscalização e a dinâmica utilizada para recrutar os estagiários na graduação. Estuda ainda aspectos vinculados ao desenvolvimento organizacional, enxergando o estágio como uma ferramenta de construção da proposta metodológica da formação do bacharel em Direito. Como metodologia a pesquisa contempla uma pesquisa documental e de campo. Visto que o número de estagiários é muito grande, quanto à consecução dos objetivos, a pesquisa será descritiva e exploratória. Os resultados, entre outros aspectos, permitiram concluir que a Lei não é cumprida na sua totalidade e pouco disseminada nas instituições de ensino, ainda é possível afirmar que o rigor na fiscalização é pequeno. Além do mais, a relação entre conteúdo do ensino e prática nas atividades realizadas nos estágios são bem destoantes e também outro fator preocupante é a satisfação dos estagiários ativos no mercado de trabalho que pode interferir ou até mesmo definir a continuidade na carreira.
\end{abstract}

PALAVRAS-CHAVE: Estudantes de Direito. Estagiários. Lei do Estágio.

\footnotetext{
* Bacharel em Direito e Administração, Mestranda do Programa de Pós-Graduação em Administração - FURG.

** Doutorado em Direito pela Universidade Federal do Paraná, Brasil (2004). Professor Adjunto III da Universidade Federal do Rio Grande.
} 


\begin{abstract}
This article has as main objective to analyze the application of the stage law and the contribution to the regulation of the stages experienced by the students of the Law Course of the Federal University of Rio Grande - Furg. It is a research developed to qualitatively evaluate the performance of the stages. Regarding the structural aspects, still in the introductory part, considerations are made regarding the global context and the profile of the trainee of Law based on the stimulus to the development of new competences. As a focus of the evaluation of the fulfillment of the stage law and the satisfaction of the trainees, the work criticizes the lack of supervision and the dynamics used to recruit trainees in the undergraduate program. It also studies aspects related to organizational development, viewing the internship as a tool for the construction of the methodological proposal of the bachelor's degree in Law. As a methodology the research contemplates a documentary and field research. Since the number of trainees is very large, in terms of achieving the objectives, the research will be descriptive and exploratory. The results, among other aspects, allowed to conclude that the Law is not fulfilled in its totality and little disseminated in the educational institutions, it is still possible to affirm that the rigor in the inspection is small. Moreover, the relationship between content of teaching and practice in the activities carried out in the internships is quite disproportionate and also another worrying factor is the satisfaction of active trainees in the labor market that can interfere with or even define career continuity.
\end{abstract}

KEYWORDS: Law students. Trainees. Law of the Stage

\title{
1 INTRODUÇÃo
}

O presente trabalho buscou verificar se a Lei do Estágio é cumprida em sua totalidade utilizando como população para a amostra os estudantes do curso de Direito da Universidade Federal de Rio Grande. Além disso, a intenção foi elencar qualitativamente os dados, através da análise dos resultados da pesquisa aplicada por meio de questionário, visando identificar as principais falhas no cumprimento da lei e comprovar se de fato as atividades do estágio são pertinentes ao conteúdo do curso. A pesquisa é de fundamental importância tanto para os estudantes quanto para as instituições que ofertam os cursos, por abordar um assunto carente de atenção dos próprios estabelecimentos de ensino e de fiscalização. A pesquisa 
confirma sua viabilidade ao agregar elementos empíricos à discussão latente sobre a formação no ensino superior em âmbito nacional e a crítica ao divórcio entre teoria e prática, em especial, no curso de Direito, onde o conhecimento efetivo da realidade organizacional é imperativo para o desenvolvimento de profissionais capacitados.

\subsection{Material e métodos}

$\mathrm{O}$ presente artigo estrutura-se em capítulos, sendo que o primeiro realiza um giro histórico sobre o tema, a fim de contextualizar e demonstrar o desenvolvimento dos dispositivos legais até os dias atuais. Com isso, o entendimento da conjuntura que levou à atual legislação vigente e que norteia o tema pode refletir as demandas históricas e culturais do país demonstrando o caráter imprescindível dos movimentos sociais urbanos silenciosos, mas eficazes em seu propósito de ajustar as normas sociais para a efetiva proteção dos desfavorecidos.

O segundo capítulo trata da relação entre o estágio e aprendizagem e sua diferenciação quanto a diversos aspectos, ao passo que estuda as formas de desvirtuamento do estágio e suas consequências, destacando o papel dos meios de controle e fiscalização e seu desempenho na integralidade. Em vista disso, será abordada a questão da função social do estágio na sociedade e sua importância para a comunidade de jovens que, mesmo com as grandes falhas, tem grande valia para a construção desses futuros profissionais e formação de experiência na área de atuação que pretende seguir. Finalmente, o próximo capítulo fará a apresentação da tabulação dos dados pesquisados através do questionário aplicado aos estudantes e por fim as conclusões dos principais pontos de abordagem caracterizando a formação do perfil do estágio no curso de Direito da Universidade Federal do Rio Grande e apontando as principais violações cometidas contra a Lei em evidência.

\section{CONTEXTO HISTÓRICO E EVOLUÇÃO DO ESTÁGIO NO BRASIL}

As relações com características de estágio apareceram por volta de 1080 no mundo originado do latim stare que significava "estar num lugar" e com o passar do tempo a palavra "estágio" se 
vinculou ao aprendizado de habilidades específicas supervisionadas, tal como é reconhecido nos dias de hoje. No Brasil, os estudos que tinham uma visão mais aprofundada e que podem ser equiparados ao nível superior foram incorporados com a chegada da realeza em meados de 1808. Com isso a tendência de preparação para o trabalho e a obrigatoriedade do período escolar se difundiu dando ênfase para a aquisição formal de conhecimento.

Surgiram os primeiros traços das normas legais para regular o estágio no Brasil através da criação do Decreto-Lei $n^{\circ} 4.073 / 42$, a Portaria $\mathrm{n}^{\mathrm{o}} 1.002 / 67$ do Ministério do Trabalho, o Decreto $n^{\circ} 66.546 / 70$, o Decreto ${ }^{\circ} 75.778 / 75$, a Lei $n^{\circ} 6.494 / 77$ e o Decreto $n^{\circ} 87.497 / 82$. O Decreto-Lei $n^{\circ} 4.073$ instituiu a Lei Orgânica do Ensino Industrial, estabelecendo as bases de organização e de regime do ensino industrial como equivalente ao secundário. O estágio escolar é incorporado na Portaria $\mathrm{n}^{\mathbf{0}} 1.002$, a qual define a importância do estágio para o aperfeiçoamento do ensino, criando condições favoráveis ao envolvimento entre a escola e a empresa. Determinou ainda que o estágio deveria ser firmado em um contrato contendo duração, carga horária, valor da bolsa e o seguro contra acidentes pessoais e estabeleceu que não existe vinculação empregatícia, encargos sociais, pagamento de férias ou de $13^{\circ}$ salário.

O estágio no Brasil ganhou força na década de 70 como forma de possibilitar experiência e captar novos talentos dentre os estudantes. Todavia, já em 1961 surgiu a Lei de Diretrizes e Bases da Educação em conjunto com a Lei Orgânica do Ensino Industrial LOEI -, voltada para os cursos profissionalizantes, regulando uma forma parecida do termo estágio como se conhece hoje. Após, foram elaborados vários decretos, mas um deles, o Decreto $n^{\circ} 75.778 / 75$ foi que permitiu o estágio no serviço público federal.

Ao mesmo tempo em que as várias legislações vieram para complementar e atualizar as diretrizes do estágio, suprindo as necessidades, essas normatizações se tornavam essenciais para manter o bom funcionamento das relações de estágio. $\mathrm{O}$ primeiro documento de 1942, o Decreto Lei 4073 chamado de "Lei Orgânica do Ensino Industrial", trata do estágio no estabelecimento industrial, já que os estagiários não possuíam qualquer vínculo empregatício com a empresa onde estavam estagiando, apenas desenvolviam treinamento nas mesmas. Percebe-se que o estágio aparece de forma 
bastante rudimentar nessa época, visto que só em 1967, foi sancionada a Portaria 1.002 de 29/09/1967. Com essa portaria, surgiu de certa forma, uma maneira de proteção ao aluno e à empresa, com a obrigatoriedade de um contrato-padrão, contendo regras para seu conteúdo, como a duração do estágio, a bolsa de ensino com o valor ofertado pela empresa, o seguro contra acidentes pessoais, oferecido pela entidade em que o estagiário exercerá sua atividade, e a carga horária deste estágio.

O estágio dentro do serviço público federal foi instituído com o Decreto $\mathrm{n}^{\mathrm{o}} 75.778 / 1975$ de 26 de maio de 1975. Entretanto, o surgimento do estagiário em todo o ordenamento jurídico se deu com a Lei 6.494/1977, sancionada em 7 de dezembro de 1977 que normatiza os estágios dos estudantes das instituições de ensino superior e profissionalizante de $2^{\circ}$ grau, mas também inclui o Supletivo. Pode-se conceituar o estágio como uma forma de complemento do ensino formal e aprendizagem de extensão. Dessa forma, os alunos são inseridos no meio social e realizam atividades de relevância para sua formação. Através da legislação, o estágio se formalizou e começou a exigência de assinatura do termo de compromisso entre estudante, a empresa, e com a supervisão da instituição de ensino. A Lei 6.494/77, em geral, não trouxe muitos avanços, o seu objetivo é propiciar experiência que possa contribuir e facilitar a assimilação melhorando o desenvolvimento do aluno, mas apesar de ter sido manifestadamente conhecida, só foi regulamentada pelo Decreto $\mathrm{n}^{\mathrm{o}} 87.497$ de 18 de agosto de 1982, conferindo-lhe mudanças quanto ao conceito de estágio curricular:

Considera-se estágio curricular, para os efeitos deste Decreto, as atividades de aprendizagem social, profissional e cultural, proporcionadas ao estudante pela participação em situações reais de vida e trabalho de seu meio, sendo realizada na comunidade em geral ou junto a pessoas jurídicas de direito público ou privado, sob a responsabilidade e coordenação da instituição de ensino.

No trecho do decreto apresentado, consta a intenção de propiciar aos jovens situações reais que sejam condizentes com sua futura profissão. Para tanto, é vital a integração social e cultural de todos os agentes envolvidos, o direcionamento do estudante para que não se desmotive e a criação de forma inovadora de sugestões para 
aperfeiçoar a prática. Nesse contexto, o aluno deixa se der mero aprendiz para tornar-se um profissional capaz de desempenhar as suas tarefas com comprometimento profissional e social.

A nova Lei de Estágios, $n^{\circ} 11.788$, publicada em 26 de setembro de 2008 e trouxe consigo inúmeras mudanças, que são consideradas muito significativas. Dentre elas, o direito a recesso de trinta dias ao estagiário que cumprir um ano em uma mesma instituição ou para aqueles que não completem esse tempo, valor proporcional na sua rescisão do termo de compromisso; a estipulação de no máximo quatro horas para estudantes do ensino médio e aqueles que pertencem à educação especial e de seis horas aos alunos de ensino superior para não prejudicar na sua rotina escolar. Mais uma mudança relevante é a supervisão obrigatória de um professor designado pela unidade concedente para fins de fiscalização e orientação, e mais um supervisor in loco que deve ser preferencialmente da mesma área de formação do aluno para poder passar maior conhecimento a este. Existe agora também a necessidade de apresentar, a cada seis meses, o relatório de atividades do estágio à instituição de ensino, contendo atividades desempenhadas e avaliação do aluno, mas a prática dessa conduta deve ser cobrada pela instituição em que o aluno está matriculado.

Outra mudança que vale a pena mencionar é a duração máxima do estágio, restringida para no máximo dois anos no mesmo local, excetuando aqueles estagiários portadores de deficiência. A Lei anterior não previa o máximo de duração, apenas o mínimo que era de seis meses. Nesta nova lei fica o contrário estipulado, não fixa mínimo de duração podendo o estagiário ou empresa quebrar o vínculo a qualquer momento respeitado o prazo de informação da desvinculação. Ainda autorizou os profissionais liberais apenas de nível superior a contratar estagiários. Por todas essas alterações, a contratação de estagiários sem os requisitos de acordo com a legislação é caracterizada como vínculo de emprego gerando todos os direitos referentes à legislação trabalhista e previdenciária. Qualquer instituição seja privada ou pública, que reincidir em qualquer irregularidade deverá ser impedida de ter estagiários por dois anos consecutivos como penalidade.

Um ponto de discussão é o aproveitamento da carga horária de estágio não obrigatório para as atividades complementares ou para 
suprir a necessidade de estagio obrigatório se antecipado. Como não fica descrito na legislação como atuar, fica a cargo das instituições fornecer essas informações no plano pedagógico em conformidade como as portarias estipuladas pelo MEC. Foi reforçada a ideia de que fica completamente proibido a cobrança de quaisquer taxas ao estudante para incorporar seleções ou cadastros de estagiários, sendo ilegal este tipo de encaminhamento e pode ser denunciado por qualquer cidadão. A Lei do Estágio garante alguns direitos ao estagiário, como a redução da carga horária em pelo menos a metade durante o período de avaliações.

Ela surgiu para tornar lícita e mais clara as relações que envolvem estudantes, observado o interposto de que estágio não é emprego, mas sim complementação da aprendizagem para o aluno, promovendo maior preparação para o trabalho produtivo. As possibilidades de ficar em desacordo com as regras contidas na lei deixaram muitos empresários apreensivos, preferindo abrir mão dos estagiários ao invés de correr riscos burlando de maneira involuntária a lei e sofrendo autuações de uma eventual fiscalização. Segundo a Lei de Estágios, $\mathrm{n}^{\circ} 11.788$, publicada em 26 de setembro de 2008, o conceito do termo estágio:

\begin{abstract}
"Ato educativo escolar supervisionado, desenvolvido no ambiente de trabalho, que visa à preparação para o trabalho produtivo de educandos que estejam frequentando o ensino regular em instituições de educação superior, de educação profissional, de ensino médio, da educação especial e dos anos finais do ensino fundamental, na modalidade profissional da educação de jovens e adultos".
\end{abstract}

A ausência de celebração do Termo de Compromisso de Estágio, e da obrigatoriedade do termo de Seguro de Acidentes Pessoais, descaracteriza o estágio, e em contrapartida, cria um vínculo empregatício, deixando a Empresa vulnerável e exposta por infringir as normas previstas na CLT. (Legislação do Estágio Inciso II e $\S 2^{\circ}$ do Artigo $3^{\circ}$; incisos I e IV do Artigo $9^{\circ}$; Artigo $15^{\circ}$, caput). Em 1980, o curso de Direito tornou-se um dos cursos mais procurados no Brasil, e em vista disso, a necessidade de postular a partir de várias portarias e leis regulamentares, realmente importantes para regulamentação do ensino jurídico, mas ainda se faz necessário vários ajustes de mecanismos dentro das instituições 
pedagógicas de adaptação as demandas atuais e reformulação de acordo com o meio que se apresenta hoje.

\section{CONCEITOS E CONTRIBUIÇÃO DO ESTÁGIO E APRENDIZAGEM X FUNÇÃO SOCIAL}

A seleção dos estagiários é um dos fatores alarmantes, pois em sua maioria é feita informalmente por intermédio de contatos de amigos ou parentes, ao contrário do que deveria ser feito, ou seja, por uma prova teórica de conhecimentos ou por entrevista baseada em quesitos avaliativos dos perfis. No entanto, a entrevista é motivo para muitas reclamações entre os estudantes também, ao passo que a aparência ganha mais pontos do que o desempenho nas atividades e disponibilidade dos participantes, ou então fica com a vaga aquele que é mais submisso aos supervisores e não causará problemas ao longo da duração do estágio. Carelli fala o seguinte sobre o tema:

Assim, o estágio pretende fazer a ligação entre o ensino teórico com
a prática profissional, sendo uma forma de complementação
curricular... Hoje vemos grandes empresas apropriarem-se do estagio
para colocação de mão de obra barata e destituída de direitos sociais,
em funções que nada acrescentam à formação do estudante, o que
não pode ser aceito.( CARELLI, 2010, p. 99)

Dentro desse panorama, cabe ressaltar a diferença entre a aprendizagem comercial e o estágio, visto que enquanto o primeiro é uma espécie de contrato de trabalho que gera vínculo temporário, o segundo é uma espécie de extensão de ensino sem qualquer garantia quanto ao fator previdenciário ou futura efetivação na empresa onde se realiza. $\mathrm{Na}$ aprendizagem é contemplado o estudante de segundo grau que tenha mais de quatorze anos e que frequente com regularidade as aulas. Normalmente esse vínculo tende a se efetivar se o estudante completar dezoito anos e atender satisfatoriamente as necessidades para o cargo ou função dentro da empresa, visto que ela visa inserir o jovem no primeiro emprego e a profissionalizar-se em uma área específica, se distanciando do conceito de estágio que prega preceitos diferentes. Nesse sentido destaca-se o Art. 19 da Lei n 11.788 de 25 de setembro de 2008, que menciona o Art. 428 da Consolidação das Leis do Trabalho CLT, aprovada pelo decreto-lei ${ }^{\circ} 5.452$, de $1^{\circ}$ de maio de 1943 : 
Art. 428. $\S 1^{\circ} \mathrm{A}$ validade do contrato de aprendizagem pressupõe anotação na Carteira de Trabalho e Previdência Social, matrícula e frequência do aprendiz na escola, caso não haja concluído o ensino médio, e inscrição em programa de aprendizagem desenvolvido sob orientação de entidade qualificada em formação técnico-profissional metódica.

Essa diferenciação acentua ainda mais a atipicidade do Estágio, que por sua vez está sofrendo regulação constante conforme demanda, por ser dispositivo legal relativamente recente e alvo de precarização e fraudes diversas mascaradas sob o manto de falta de informação, debate e fiscalização desse instituto como relata Carelli no trecho a seguir:

O contrato de estágio é aquele em que um estudante regularmente matriculado em cursos de educação superior, de ensino médio, de educação profissional de nível médio ou superior ou escolas de educação especial é admitido em pessoas jurídicas de direito privado ou na administração pública, para complementação prática na sua linha de formação. (CARELLI,2010, p. 100)

Além de todos os entraves para o aperfeiçoamento da atividade de estágio, existem também empresas que estão aproveitando a tendência de contratar estagiários para expandir sua atuação. Segundo Carelli: "Infelizmente existem agentes de integração atuando como verdadeiras agências de colocação de pessoal na empresa, lucrando com a inserção de estudantes e se descuidando das suas obrigações de cumprimento da lei de estágio... Essa atuação maléfica e irregular deve ser coibida, para evitar o desvirtuamento dessas instituições e do próprio estágio." (CARELLI, 2010, p. 102)

\subsection{Assédio moral no estágio}

O assédio moral pode estar presente em todas as formas de trabalho, sejam atípicas como estágio e aprendizagem comercial ou não, como o celetista e servidor público. Esse tipo de acontecimento caracteriza-se pela humilhação sofrida por um funcionário repetidas vezes e não como um ato isolado e pode ocorrer de muitas maneiras: bronca, ameaça, espalhar boatos contra o funcionário ou mesmo tirar 
objetos de trabalho, como a mesa ou o telefone, para constranger em público ou não. Alguns sinais podem se caracterizar como assédio, como por exemplo: não dar tarefas induzindo o estagiário ao ócio, perseguições dos superiores ou colegas, imputar erros sem fundamento ao estudante constrangendo o mesmo, instruir erroneamente para efetuar tarefas visando prejudicar, forçar $o$ estagiário a pedir desligamento, fazer brincadeiras inapropriadas em tom de humilhação e diversas atitudes que não condizem com uma postura profissional. Embora haja muita incidência de assédio, deve ser analisado com cuidado para não confundir com críticas construtivas e ações de prevenção de erro que vem sendo difundidas nas empresas e instituições de grande porte.

A prevenção do assédio moral se dá com a visitação do professor orientador do estágio no local de trabalho do estagiário, conhecendo sua rotina, o ambiente e seus supervisores, assim ele irá auxiliar reportando à instituição os relatos que fez e suas impressões. Mas, infelizmente não são todas as instituições e agentes de integração que tem essa preocupação ou possibilidade, alguns dos orientadores são figurantes nessa relação, apenas servindo para cumprir uma obrigatoriedade. Se o estudante se sentir desamparado em relação à sua instituição de ensino e a empresa não colaborar para a resolução do conflito, existe a possibilidade de denunciar o caso ao Ministério Público, e em casos mais drásticos promover ação por dano moral e a empregadora será responsabilizada judicialmente pelas suas atitudes. Mas, muitos jovens não denunciam os casos por medo de serem prejudicados no futuro profissional, visto que esse pensamento é senso comum na sociedade, e vem sendo reformulado aos poucos com a construção dos direitos sociais.

Em suma, todo cuidado dispensado ao assunto é válido por se tratar de jovens, que ao ingressar no mercado de trabalho e se deparar com condutas impróprias incorporam, de forma negativa, características que vão influenciar na sua personalidade e carreira profissional. Ainda cabe ressaltar que se o estudante passa por uma situação constrangedora e essa é tratada de forma adequada, com diálogo e termina de forma simples e rápida, possivelmente repetirá essa conduta nas futuras relações de trabalho gerando um ciclo positivo e harmônico dentro do ambiente em que estiver inserido. Existe também a ocorrência do drama referente ao assédio 
horizontal, que é praticado por estagiários contra estagiários, incentivado pelo espírito de competição instaurado na empresa, seguindo a regra do capitalismo embutido na sociedade e cada vez mais legitimado, que pode acontecer e não é raro, tornando-se intensificado pelos preconceitos individuais seguindo orientações de cor de pele, classe social, religião ou política. Este por sua vez, deve ser desencorajado e repreendido seguindo os padrões éticos que devem ser respeitados dentro de quaisquer relações profissionais.

\subsection{Desvirtuamento do estágio}

Seguindo as determinações da Lei $\mathrm{n}^{\circ}$. 11.788/2008, o estágio deve ter duas divisões apenas: obrigatório ou não obrigatório. A maioria das ocorrências de desvirtuamento do estágio acontece na modalidade não obrigatória, tem-se uma grande dificuldade em controlar a inobservância do vínculo empregatício e desvio de finalidade. O agravamento dessa situação aumenta desproporcionalmente, visto que a contratação de um estagiário pode ser com intuito de burlar as obrigações trabalhistas e previdenciárias.

Ao traçar um paralelo entre o antes e depois das modificações trazidas com a nova "Lei do estágio", notam-se grandes mudanças, tais como: o perfil dos candidatos era basicamente composto por jovens regularmente matriculados em instituições de ensino médio, educação superior, profissional e especial, mas foi ampliado para estudantes de ensino fundamental na modalidade profissional, estrangeiros matriculados em instituições de ensino brasileira e com visto de permanência dentro da validade; foi estipulada a carga horária de 6 horas diárias/30 horas semanais; na duração do estágio deixa de existir tempo mínimo de um semestre e institui o máximo de dois anos no mesmo local; a composição do perfil dos contratantes era composta por empresas privadas e órgãos da administração pública da União, dos Estados, do Distrito Federal e dos Municípios, e com a nova lei agregou os profissionais liberais de nível superior que tiverem registro em seus conselhos de fiscalização.

Como medida para combater a desvirtuação, a legislação discorre sobre precauções tomadas visando repelir a contratação de estagiários como empregados disfarçados, como a que limita o número de estagiários à proporção de empregados. Com isso, quem 
dispõe de um a cinco empregados poderá ter um estagiário contratado e assim por diante, até as que possuírem mais que vinte e cinco empregados poderão ter a cota de $20 \%$ de estagiários. A obrigatoriedade de remuneração no estágio não obrigatório e de pagamento do vale-transporte para os estagiários aumenta consideravelmente os custos com a contratação dos mesmos, tornando menor a contratação de estagiários em alta proporção e o suprimento de postos de trabalho efetivo. A concretização do direito a férias remuneradas marca a maior evolução aos direitos dos estagiários, afinal eles possuem como todos os outros trabalhadores necessidades biológicas e sociais de descanso preferencialmente em suas férias escolares.

Mesmo que a lei não tenha sido aplicada nos contratos em andamento, mas vigorando a partir das suas prorrogações e renovações e aos contratos realizados depois de sua publicação, ela deu amplitude à proteção do estudante, conferindo direitos semelhantes aos empregados celetistas e inovando em medidas para minimizar os contratos de estágio fraudulentos. Dentre as alterações, a de possibilitar que os profissionais liberais de nível superior registrados também contratem estagiários é muito importante, pois estes poderão passar por vivências diferentes e aprender na prática a rotina de um autônomo, além de estimular o empreendedorismo. Para isso, eles devem cumprir as mesmas regras das instituições, contratar termo de compromisso com a instituição de ensino e o aluno, proporcionar instalações com condições de possibilitar a aprendizagem profissional e a contratação de seguro obrigatório de acidentes pessoais. Essa questão do seguro de acidentes pessoais obrigatório é exigindo que a apólice esteja escrita no contrato de estágio deve seguir os valores de mercado. Enquanto que a norma anterior dizia abstratamente que deveria existir um seguro, mas nada falava em valores, esta estipula e torna essa regra mais fácil de ser fiscalizada. Apesar de a seleção obrigatória da $\mathrm{OAB}$ para os egressos possuir grande valia para assegurar a entrada de profissionais qualificados no mercado, também revela a urgência em melhorar o ensino inserindo o estudante no "mundo do estágio" como preparação para o futuro que é incerto e tem concorrência acirrada, como se percebe na fala de Vasapollo, onde destaca que "a nova condição de trabalho esta sempre perdendo mais direitos e garantias sociais” (VASAPOLLO, 2005, p. 10). 
A atual incerteza que o mercado de trabalho oferece na atualidade traz consigo a falta de assistência e garantia social. Isso torna o trabalhador mais vulnerável à precarização e a exposição às situações precárias, de forma que o trabalhador se "obriga" a suportar certas condutas por necessidade, ciente de que talvez não consiga se reinserir no mercado tão rapidamente caso seja desligado. Se for comparado o gasto de um empregador ao contratar um funcionário, muitas vezes regido por sindicatos com piso salarial pré-determinado, e um estagiário, praticamente com custo zero de tributos e valor de bolsa pequeno sem grandes abalos em seu orçamento, fica fácil entender o porquê de tanta desvirtuação. Ainda porque o estudante via de regra dispõe de uma energia e renovação intelectual, além da maior facilidade de adequação a mudanças que refletem como vantagens da idade e situação em que se encontram. A maior preocupação da nova lei é repelir tanto o trabalho infantil, quanto a precarização do trabalho, e em vista da falta de critérios específicos em muitas lacunas da nova lei, possivelmente haverá uma atualização brevemente visando alinhar melhor com as necessidades, mas isso é comum e aceitável, já que ela precisa de um tempo para verificar sua eficácia.

\section{RESULTADOS E DISCUSSÕES: CONTRIBUIÇÃO ACERCA DOS ASPECTOS DA PESQUISA SOBRE O ESTÁGIO NÃO OBRIGATÓRIO NO CURSO DE DIREITO NA FURG}

O estágio no Brasil passou a ser um assunto pouco debatido, visto que as empresas estão confortáveis com a atual situação, ou seja, ter um jovem estagiário especializado exercendo a função de um funcionário muitas vezes melhor do que o mesmo por um preço menor sem encargos trabalhistas e bonificações correspondentes ao vínculo empregatício. Rodrigo Carelli afirma que: "A introdução da referida norma não exclui os demais requisitos impostos pela lei, permanecendo a necessidade de se proporcionar experiência prática na linha de formação do estagiário, complementando o ensino, de acordo com a estrutura curricular". (CARELLI, 2004, p. 60)

\subsection{Análise dos dados}

A presente pesquisa qualitativa foi realizada com a aplicação de um questionário semiestruturado para os alunos do Curso de 
Direito da Furg durante os meses de agosto e setembro de 2016. Foi estabelecido como requisito para os respondentes: estar estagiando no momento ou já ter estagiado durante o curso visando abranger maior número de pessoas. Nesse contexto, durante a aplicação se obteve uma cooperação favorável à discussão do tema e evidenciou a necessidade de esclarecimentos sobre a temática e a legislação vigente, pois poucos alunos conheciam esses fatores, conforme mostra o resultado dos dados obtidos do questionário. Para tanto, responderam ao questionário 72 alunos do Curso de Direito nos turnos noturno e diurno, totalizando uma amostra coerente com o proposto.

$\mathrm{O}$ que mais chamou atenção, dentre as muitas questões abordadas, foram as respostas dos respondentes quando questionados se conhecem na íntegra a Lei do Estágio, e a partir dos resultados, sendo que do total de 72 (setenta e dois) alunos, apenas 24 (vinte e quatro) alunos já leram a lei, lembrando que todos que responderam o questionário estão no momento estagiando ou já estagiaram. Sendo assim, aduz a gravidade da situação e total desinformação do estagiário quanto aos seus direitos e obrigações de forma preocupante como demonstra claramente o Gráfico abaixo:

GRÁFICO 1: Conhecimento da Legislação

\section{Conhece na íntegra a Lei do Estágio}

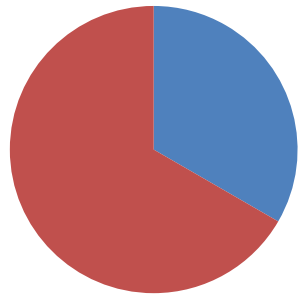

SIM 33\%

NÃO 67\%

FONTE: Autora

Isso releva que as informações passadas ao estagiário são normalmente informadas pelo seu supervisor no local de estágio, e não são contestadas pelo estudante, em geral por medo de perder a oportunidade ou por falta de comunicação e acessibilidade aos seus 
"superiores". Com esse tipo de abordagem, existe muito desvio de finalidade presente hoje nos estágios, mas alguns aspectos levantados durante a aplicação dos questionários valem a pena como alarmantes, se o jovem acostumar-se e internalizar as ações erradas cometidas nos ambientes pelos quais passou, vai repetir o que viu e sofreu com os seus sucessores. Nessa perspectiva, o resultado da tabulação de dados referentes ao cenário atual do clima organizacional demonstra que a satisfação dos estudantes quanto à harmonia do ambiente é fragmentada e se dividiu em $25 \%$ dos estagiários que classificam como ótimo, $33 \%$ como bom, $30 \%$ como regular e $12 \%$ como ruim.

Uma situação de estresse contínuo, mesmo que fundamentada a partir de uma alegação de competição ou concorrência por uma vaga efetiva não é saudável, trazendo malefícios imensuráveis para a formação de caráter de uma pessoa e para sua saúde, pois o estresse causa sintomas comprovados, como por exemplo: depressão, dor de cabeça, tontura e inúmeros distúrbios digestivos dentre outros muito mais graves. Para agregar consistência a essa discussão, foi feito levantamento dos alunos que dizem já ter sofrido assédio moral enquanto estagiários, e os números do gráfico abaixo reforçam o tudo o que foi exposto.

GRÁFICO 2: Ocorrência de Assédio Moral

\section{Sofreu assédio moral no estágio}

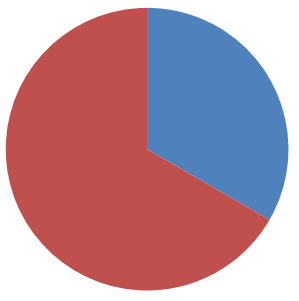

SIM 33\%

NÃO 67\%

FONTE: Autora

Os dados colhidos servem de parâmetro para dimensionar questões pontuais, mesmo porque são de suma importância para verificação das irregularidades nos estágios. Tendo por base que o ponto central é a comprovação ou não de que a aplicação da lei está sendo respeitada, em relação à diminuição da jornada em dias de 
prova, $45 \%$ dos respondentes disseram que há respeito a essa regra da lei, mas 55\% alegaram que não possuem esse benefício. Então, o que pode se depreender é que há desleixo com a qualidade do aprendizado por parte de quem contrata os estagiários, ainda permite a conclusão de que a finalidade da contratação dos estagiários muitas vezes não tem como prioridade oportunizar ao estudante experiências, mas sim um trabalhador comum que tem obrigação de cumprir sua carga horária.

Em razão disso, a "promiscuidade do estágio" permeia na sociedade e traz consigo a exploração de mão de obra. Um dos artigos da Lei $n^{\circ} 11.788 / 2008$, art. $10, \S 2^{\circ}$, versa sobre a garantia de férias ao estudante após completado um ano de estágio ou férias proporcionais em caso de rescisão do contrato, apurados os resultados desse item, tem-se que este artigo em quase sua totalidade é respeitado, ou seja, $72 \%$ dos estudantes já tiveram férias ou receberam proporcionalmente quando deixaram o estágio, ainda dentre os $18 \%$ que ainda não tiveram, alguns relataram não ter cumprido um ano integralmente.

No quesito abordado em relação às atividades que constam no plano de trabalho do estágio, e as que realmente são exercidas no dia a dia, encontra-se um dos pontos mais relevantes para a pesquisa e refere-se aos desvios nas funções. As atividades descritas no plano de trabalho são fornecidas pelo contratante do estagiário, presumindo que este irá seguir o que foi estipulado inicialmente, acrescentando apenas o que for contribuição para o desenvolvimento e crescimento dos conhecimentos do aluno. Mas na prática as coisas não acontecem como listadas no papel, dos setenta e dois alunos, quarenta e seis realizam tarefas que não lhe cabem como estudante e desvirtuam de sua função de estagiário, como por exemplo: servir café, atender telefone, cumprir a tarefa de secretária, carregar processos, fazer sentenças, tirar xerox durante o dia todo e muitas outras, para melhor visualização observe o gráfico abaixo: 
GRÁFICO 3: Atividades do Plano de Trabalho

\section{Faz atividades que não pertencem ao seu plano de trabalho}

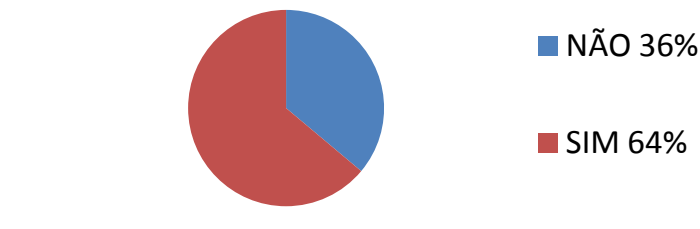

FONTE: Autora

Um dos fatores que contribuem para essas "aberrações" é a falta de fiscalização por parte da unidade concedente por várias razões que amenizam a culpa, ao passo que o número de professores não é suficiente para fazer esse controle, a estrutura não facilita o deslocamento até os locais de estágio, não possuem penalidades ou sanções definidas para os desvios. Portanto, fica imperativo a revisão desses métodos e intensificar a busca por soluções possíveis para amenizar a incidência desses acontecimentos.

Quando questionados sobre o conhecimento do nome do professor orientador, $42 \%$ dos respondentes disseram não saber. Esses dados representam o reflexo da atual crise financeira no sistema educacional público. A intenção é chamar atenção para a necessidade de aproximação dos discentes e docentes dentro da instituição e repensar o procedimento atual, buscando modificar essa perspectiva. Nesse sentido, os resultados obtidos não podem ser considerados satisfatórios e ao contrário, foram encontradas evidências da falta de assistência ao estudante em seus estágios não obrigatórios. No questionamento relacionado à supervisão no Local de Estágio, $72 \%$ disseram ter supervisor atuante no local do estágio e $28 \%$ revelaram não ter alguém exercendo essa função.

Quanto ao Pagamento de Bolsa-auxílio ao estudante, em contraposição ao salário, esta não possui encargos e tributos que normalmente o empregador teria que arcar com um funcionário contratado sob as normas da CLT. Segundo as alterações da lei, fica obrigatório o pagamento de bolsa nos estágios, como alternativa para impossibilitar a proliferação do estágio voluntário, mas mesmo com 
$81 \%$ afirmando receber a Bolsa-auxílio, $19 \%$ não recebem e apenas tem perspectiva de que irão receber no semestre posterior, pois no momento são voluntários.

Muitos consideram o estágio importante por inserir o estudante no primeiro emprego, mas essa informação é disseminada de forma errônea, pois é a aprendizagem comercial que melhor se encaixa nesse conceito. $\mathrm{O}$ estágio não gera vínculo empregatício, não tem anotação na carteira de trabalho, não faz contribuições e não gera encargos trabalhistas por parte da empresa. Segundo o art. $3^{\circ}$ da CLT, define o empregado como: "toda pessoa física que prestar serviços de natureza não eventual a empregador, sob a dependência deste e mediante salário". O estagiário recebe bolsa auxílio para que possa custear seus gastos com alimentação e despesas pessoais, mas não tem caráter assalariado. A Legislação não estipula datas para os pagamentos da bolsa estágio ou das eventuais rescisões contratuais. Portanto, caso não conste no Contrato de Estágio, por analogia, pode-se aplicar os prazos da CLT, que se refere ao quinto dia útil do mês subsequente ao vencido para o pagamento da bolsa estágio e 10 dias corridos contados da data da rescisão para o pagamento das férias e dias trabalhados proporcionais.

O estágio sem regulamentação é instrumento duvidoso, porque tanto pode contribuir para a formação profissional ou para precarização do trabalho, a partir daí a fiscalização e a punição eficiente se tornam indispensáveis para a consecução do objetivo almejado. Mas, como fator principal é fundamental à conscientização dos atores interessados na relação. A descrença na legislação, incutida em muitos estagiários é o principal motivo para a continuidade das violações. Especialmente o estagiário de Direito, tem uma gama de opções para estagiar e ainda mais depois de formado, quando o leque se abre para diversas carreiras jurídicas. Com isso, o fato de estagiar também é benéfico para o fortalecimento da certeza na escolha de carreira, experimentar o dia a dia de algumas possibilidades para identificar-se ou não com a rotina e exigências requeridas para a função, dessa forma poderá tomar uma decisão mais madura e concisa com seus interesses para seu futuro. 


\section{CONCLUSÕES}

Em suma, por tudo que foi analisado, comprova-se que há uma incidência numerosa de desvirtuamento da atividade de estágio não obrigatório e também a ocorrência de desrespeito aos artigos da Lei ${ }^{\circ}$ 11.788 , de 25 de setembro de 2008. De outro lado, observam-se as falhas no acompanhamento pedagógico da instituição quanto à fiscalização das condições as quais o estagiário é submetido. Portanto, a falta de alinhamento entre o plano de trabalho do estágio e as atividades desempenhadas na prática pelos estudantes, deixa claro a inobservância das normas e caracteriza o desvirtuamento ou possível fraude às normas trabalhistas se os fatos decorrerem de má-fé com a intenção de mascarar o vínculo empregatício.

A atual legislação, embora não seja abrangente como deveria, ensejou modificações importantes e resguardou garantias mínimas necessárias para assegurar o êxito dessa atividade, preservando os direitos do estudante enquanto estagiário. Mas, é evidente que não foi o suficiente para acabar com a gama de estagiários que estão na condição de empregados e não ganham os mesmos direitos, ou seja, trabalham e são cobrados como celetistas, mas recebem pagamento como estagiários. A legislação tem como um de seus objetivos, propiciar ao estudante o conhecimento prático para não ingressarem na vida profissional totalmente inexperiente, e nesse sentido, é cumprida em sua integralidade, atingindo o que se propõe. $O$ fator problemático é a utilização do estágio de forma inapropriada pela concedente, que visa lucro e sua comodidade em detrimento do aprendizado de alguém.

O ponto forte dessa pesquisa foi obter a informação, mesmo que informal sobre o tratamento que os estagiários recebem, já que mesmo os estagiários com carteira da Ordem dos Advogados do Brasil são obrigados a contribuir para manter seu vínculo, não possuem qualquer acompanhamento ou visita de um membro para fiscalizar suas atividades no estágio profissional, demonstrando assim, que a função social do estágio não é cumprida, mas por problemas na fiscalização e não por falta de regulamentação. As instituições ligadas ao ensino educacional ainda estão se adequando às mudanças, e de certa forma enfrentando obstáculos de infraestrutura e precariedade do ensino público no Brasil, para complementar os empresários e órgãos públicos 
também têm uma visão muito burocrática, com dificuldades para ver os alunos de forma dinâmica, motivacional e inovadora.

Em virtude disso, torna-se imperativa a cobrança do estudante e a denúncia das irregularidades sem receio de represálias às instituições de ensino, sendo que estas devem preocupar-se com a saúde psicológica de seus alunos, pois representam o polo mais fraco dessa relação, buscando implantar as devidas providências de acordo com a gravidade de cada caso. Mas a desinformação ainda é expressiva, de forma que deve ser corrigida dentro do ambiente acadêmico com orientação e direcionamento para dar confiança e respaldo aos alunos.

Já com relação ao prazo de denúncia existe uma lacuna na legislação, o que torna possível a aplicação do artigo 205 do Código Civil, estipulando o prazo de dez anos para o estagiário reivindicar os seus direitos. Em contraposição, existem divergências que defendem a ideia de que sendo essa uma ação de reclamação trabalhista, deve seguir os prazos processuais do direito do trabalho, estipulando que o ajuizamento na vara do trabalho tem o prazo de até dois anos contados da rescisão ou do encerramento do Contrato de Estágio para ser interposto.

No momento que o estudante perde a prioridade educativa e lhe é imposto o trabalho, o seu rendimento em suas atividades escolares tende a diminuir conforme é a pressão e sobrecarga de trabalho sofrida. Tendo em vista que a erradicação dos problemas que atingem tal assunto é improvável, o intuito é coibir práticas desonestas e qualificar o processo de estágio dando as ferramentas ao estudante para adquirir conhecimento.

Entretanto, cabe ressaltar a existência de limitações nessa pesquisa, em vista da limitação da amostragem, restringindo apenas aos estudantes do curso de Direito da FURG. A sugestão proposta ao fim do ciclo de análise para as pesquisas futuras a cerca do tema, é a incorporação, em todas as instituições de ensino, de pesquisas para verificar as deficiências que existem em sua comunidade escolar e o debate para melhor saná-las e conhecer o padrão de comportamento na sua região. Assim, com todos esses cuidados, inibiria a conduta delituosa dos empresários e entidades públicas que usufruem da mão de obra estagiária e faria existir maior adequação frente à legislação e regulamentações do estágio. 
Dentro desse novo paradigma, grandes são os desafios para aperfeiçoar a aplicação e cumprimento da Lei n 11.788 de 25 de setembro de 2008. Ainda muitas reformulações virão para harmonizar com a construção social. Diante desse cenário, como já mencionado, espera-se que o presente trabalho, fruto de uma monografia, tenha contribuído para ensejar o espírito de mudança e evolução das práticas adotadas atualmente. Haja vista que existem muitas questões para serem discutidas, mas ao dar ênfase aos questionamentos trazidos através dessa pesquisa, pode-se concluir que a aplicação dessa Lei em especial está sendo respeitada em alguns aspectos mais que outros. A realização de estágios, apenas em áreas específicas e sem o real aprendizado, limita os conhecimentos após a conclusão do curso e, consequentemente, compromete a formação integral do aluno.

\section{REFERÊNCIAS BIBLIOGRÁFICAS:}

CAPONE, Luigi. A fraude à lei do estágio e a flexibilização do direito do trabalho. Disponível em: Revista do Tribunal Regional do Trabalho. $3^{\text {a }}$ Reg., Belo Horizonte, v. 51, n 81, p. 47-70, jan/jun 2010.

CARELLI, Rodrigo de Lacerda. Formas atípicas de trabalho. $2^{\mathrm{a}}$ ed. LTR, SP, 2010.

COSTA, José Ricardo Caetano e COSTA, Eder Dion de Paula. A utilização do trabalho de estagiários sem a obediência dos requisitos legais: real aprendizado ou vinculo empregatício disfarçado? Revista Uni Curitiba. Curitiba, v. 3, n 36, 2014.

DELGADO, Mauricio Godinho. Curso de Direito do trabalho. São Paulo: LTr, 2010.

LUZ, Valdemar P. da. Estágio em direito: manual do estagiário. Barueri: Manole, 2009.

MARTINS, Sergio Pinto. Estágio e Relação de Emprego. $3^{\circ}$ ed. São Paulo: Atlas, 2012.

VASAPOLLO, Luciano. $O$ trabalho atípico e a precariedade. $1^{\circ}$ ed.- São Paulo: Expressão Popular, 2005.

BRASIL. Constituição (1988). Constituição da República Federativa do Brasil. Organização de Alexandre de Moraes. 16 ed. são Paulo: Atlas, 2000. 
BRASIL. Consolidação das Leis do Trabalho. Decreto-lei $\mathrm{n}^{\circ} 5.452$, e $1^{\circ} \mathrm{e}$ maio e 1943. Aprova a consolidação das leis do trabalho. 104. E. São Paulo: atlas, 2000. Coletânea e Legislação.

BRASIL. Código Civil. Organização e Sílvio e salvo Venosa. São Paulo: Atlas, 1993. 